\title{
Cine y Medios Sociales: Reinventando el Marketing Promocional
}

\section{Antonia Salvador Benítez}

\section{Resumen}

El sector cinematográfico necesita tomar conciencia de la importancia del marketing y las posibilidades que ofrecen los medios sociales para crear expectación y atraer a los espectadores a las salas. En este artículo se analiza el estado de la cuestión y se presentan algunas claves para la promoción online del cine tomando como referencia algunos ejemplos y estudios de caso.

\section{Palabras clave}

Cine; Marketing de cine; Marketing online; Medios sociales; Promoción

\section{Film and Social Media: Rethinking the Promotional Marketing}

\author{
Abstract \\ cases study. \\ Keywords \\ Film; Filmarketing; Marketing online; Social media; Promotion
}

The film industry needs to enhance awareness of the importance of marketing and social media to create expectation and capture the interest of audience to the cinema. This paper assesses the state of the art in online promotion and provides guidelines to create an effective film marketing campaign through some

http://dx.doi.org/10.5209/rev_CDMU.2013.v24.46285 


\section{INTRODUCCIÓN}

El cine asiste un poco tarde al fenómeno del marketing online. Aunque existen ejemplos de películas apoyadas por importantes campañas de promoción 2.0 que han obtenido un gran éxito de taquilla, la industria aún no lo ha asimilado. En el último año se han celebrado las I Jornadas de marketing online para la promoción del cine español, y la Academia de las Artes y las Ciencias Cinematográficas de España ha dedicado un número monográfico de su revista - Academia. Revista del Cine Español (junio, 2013)- a informar y concienciar a los profesionales del sector de las ventajas de la comunicación online aplicada al audiovisual.

El 90\% del marketing es sentido común: sin marketing no hay espectadores, sin espectadores no hay películas, sin películas no hay industria, y sin industria no hay trabajo. El sector audiovisual en general y el cine en particular necesita tomar conciencia de la importancia de la promoción y de las posibilidades de comunicación que ofrecen los medios sociales para atraer al público e incrementar las ventas de taquilla. Una buena campaña de promoción exige inversión, pero también un cambio de planteamiento, de forma que se considere como una puesta en valor y no como un gasto.

En la última década la comunicación ha dado un giro de 360 grados y actualmente existen infinidad de posibilidades para comunicar ideas, mensajes y conceptos, por lo que más que hablar de planes de publicidad o de promoción, se debe pensar en una estrategia integral de comunicación (Iglesias, 2013).

En el contexto actual, el medio digital es imprescindible y debe ser considerado el eje de comunicación de cualquier campaña. El empleo de las redes sociales evoca emociones, genera ideas, opiniones, expectativas, comunidades, vínculos y afinidad, que integrados con los medios tradicionales y una buena campaña de RRPP puede lograr impactar al público para llevarlo a las salas. El objetivo es crear expectación y despertar el interés del espectador.

Pero, ¿cómo crear esa expectación? En primer lugar es necesario un cambio de mentalidad de los productores y distribuidores para que vean el presupuesto de comunicación como un área de oportunidad. En segundo lugar, requiere de expertos en publicidad y promoción que sepan manejar tanto la inversión como la comunicación. En Estados Unidos lo saben muy bien, por eso, desde hace años trabajan con expertos y dedican una partida considerable a la promoción, que está prevista de antemano dentro de los costes de producción. Además consideran la campaña digital como una extensión de la propia película, creando nuevos modelos de comunicación y logrando éxitos millonarios de taquilla que no necesariamente tienen que ver con la calidad de la película.

El poder impactar a ese público objetivo no depende necesariamente del tamaño del presupuesto destinado a comunicación, sino de cómo se invierta. Los fondos deben ser utilizados de forma estratégica a partir de un análisis previo que permita conocer dónde lanzar el mensaje, cómo decirlo y cuándo es el mejor momento para hacerlo. Así, los recursos serán aprovechados al máximo. 
En el cine español el marketing es una asignatura pendiente y la publicidad o la promoción de la película suele ser lo último que se hace y sin apenas presupuesto. Es cierto que la industria no lo tiene fácil para hacer grandes inversiones en promoción, pero ahora dispone de herramientas suficientes para llegar al espectador, sin dejar de lado la gran importancia que han adquirido las redes sociales. El sector debe diseñar un plan de comunicación y marketing online que apoye la promoción de las películas que se van a estrenar en las salas.

\section{COMUNICACIÓN Y PROMOCIÓN: ACTITUD 2.0}

El elemento de comunicación comprende un amplio número de acciones -offline y online- para atraer a la audiencia y fomentar la demanda: desde un spot de televisión, noticias en prensa, transmisión de tráilers, vallas y carteles cinematográficos, acciones de street marketing, campañas de relaciones públicas y eventos en la calle hasta las acciones de marketing online. El éxito de una campaña radica, en gran medida, en una adecuada combinación de todos los medios, integrados en una estrategia multicanal.

Sin duda, la rapidez y la inmediatez de los medios sociales (blogs, redes sociales, youtube, etc.) han revolucionado la comunicación. Los contenidos circulan a gran velocidad y con la misma rapidez se quedan obsoletos. Esto obliga a construir las campañas con muchos más contenidos promocionales que los empleados hace unos años.

La comunicación unidireccional ya no parece suficiente para enganchar al público (Bretones, 2013) y la creatividad va más allá de pensar una idea o un mensaje. En muchos casos las propuestas de marketing online se construyen sobre acciones offline ya existentes a las que se agregan nuevas formas de interacción con el público y nuevos canales de difusión complementarios enfocados al mercado digital.

Si en la década pasada era indispensable que una película no tuviera su propia página web, ahora no se concibe que no tenga su propio Facebook y Twitter, y según la película, además su canal de YouTube, Pinterest, Instagram, Tumblr, estar dada de alta en redes sociales cinéfilas -GetGlue o Gomiso-y Vine, la red social de microvídeos (Crespo, 2013).

El desarrollo de un concepto y una táctica de comunicación también implican la forma en que se combinarán los diferentes medios para llegar a todos los posibles usuarios. Los mensajes siempre deben ser concebidos en torno al medio al que irán dirigidos, por lo que es fundamental conocerlos muy bien, casi tanto como al mercado mismo. Con todos y cada uno de los medios trabajando a favor de un concepto, el éxito de una campaña está asegurado (García Fernández, 2013).

Las principales agencias y estudios de Hollywood entienden las campañas digitales como una extensión de la película y cada vez sacan más partido al potencial de las redes sociales buscando el vínculo emocional y el compromiso con la audiencia. Los objetivos de estas campañas de promoción son crear expectación y viralizar, es decir, conseguir que los contenidos publicados en las redes sociales se compartan y extiendan rápidamente y como resultado, construir la audiencia de la película. A mayor vínculo emocional, más se comparte y mejores resultados puede tener en taquilla. 
Pero no basta con tener una presencia virtual para comenzar a obtener beneficios. El mercado virtual no es distinto del mercado real y los cambios de comportamiento requieren un tiempo de adaptación, esfuerzo, perseverancia y sobre todo, contenidos de calidad.

El posicionamiento web, las redes sociales o la publicidad online son herramientas clave para la promoción y comunicación aunque, ninguno de estos instrumentos serían eficaces sin un contenido de calidad. Es el denominado content marketing, una técnica muy utilizada en la actualidad en el sector de la publicidad y las actividades promocionales que consiste en crear y distribuir contenido relevante y valioso para atraer a nuestro público objetivo (Sanagustín, 2010).

El valor de los contenidos se refleja en el seguimiento que hacen los usuarios de una web, plataforma o red social concreta y la interacción con el contenido que se publica aportando valor con sus comentarios, lo que a su vez genera una difusión gratuita que se extiende y viraliza rápidamente al resto de los internautas. Como señala Crespo (2013) la clave del éxito de una campaña es crear contenido que se pueda compartir, que aporte información, genere interés, entretenga y, sobre todo, que cree empatía del espectador hacia la película.

\section{EL BRIEFING DE LA PROMOCIÓN ONLINE DE UNA PELÍCULA. UNA PROPUESTA}

La promoción es una labor que suele empezar varios meses antes del estreno o incluso desde la fase de rodaje. Pero ¿Cómo crear la expectación para que la audiencia asista a una sala de cine y elija un título determinado? ¿Cómo rentabilizar el presupuesto invertido en la promoción de una película?, ¿Cómo debe ser la comunicación de los mensajes promocionales?, ¿Qué medios se deben utilizar? Para tratar de dar respuesta a estas cuestiones a continuación señalamos siete aspectos clave que deben abordarse para el diseño y desarrollo de una estrategia de comunicación y promoción online efectiva y rentable.

\section{¿Cuánto vamos a invertir en la promoción? Asignar presupuesto}

Desde el inicio del proyecto, la partida de fondos destinada a las actividades de promoción debe estar contemplada en el presupuesto total de la película. De este modo es posible planificar el alcance de la estrategia, formular objetivos concretos y rentabilizar el presupuesto con las acciones más efectivas para el público objetivo. Una buena campaña debe plantearse como una puesta en valor y no como un gasto.

\section{¿Qué queremos contar? Definir el producto-película}

El cine es una industria y por tanto, una película debe recibir el mismo tratamiento que cualquier otro producto de consumo. Sin embargo, cada historia - de terror, animación, comedia, aventuras, musical, etc.debe considerarse como un producto independiente, con características específicas y para un público determinado. Hitchcock le decía Truffaut: "Hacer un filme no es un juego entre dos -el director y su película-, sino entre tres -el director, su película y el público-". Esta es la máxima de la promoción online de películas. El público es la razón de ser y por ello es muy importante tenerle en cuenta desde el momento en que la película comienza a gestarse.

\section{¿A quién nos queremos dirigir? Conocer al público objetivo}

Identificar, conocer y aprender del público objetivo es una cuestión esencial al iniciar el proceso de la creación. Todas las historias tienen un nicho en el mercado. Por eso es necesario recabar toda la información 
del mismo: quién consume o podría consumir el producto, perfil psicosocial (actitudes, intereses, deseos, motivaciones), contexto social y cultural, grupo social de referencia, estilo de vida, hábitos de consumo, etc. También conviene valorar qué podría incluirse en el guión o en la producción de la película que, a priori, captara su atención -actores, música y localizaciones que le atraen- y a partir de ahí plantearse cómo conectar con a él. No se trata de corromper los proyectos o la creatividad, sino de integrar de forma consensuada lo que al público le gusta (Gutiérrez, 2013).

\section{Al gusto del respetable. Testar el resultado}

Testar la película con público objetivo antes del estreno es una forma directa de obtener información para enfocar la comunicación de cara al estreno en salas. El público dará una visión objetiva de qué funciona en la historia y qué no, si la audiencia es más femenina o masculina, si el mensaje ha quedado reflejado o si es acertado el título elegido. Esta retroalimentación es muy valiosa para tomar decisiones e incluso, replantear la película, así como utilizar los elementos más atractivos en la campaña de comunicación. También puede ayudar a optimizar el presupuesto enfocando las acciones al público objetivo y centrando la campaña en los medios dónde vayan a verla.

\section{¿Cómo lo vamos a comunicar? Elaborar el mensaje}

Esta cuestión conlleva la formulación del contenido del mensaje y el modo en que va a ser expresado de una forma creativa para conseguir atraer al público y despertar su interés. Cada película debe tratarse como un producto independiente, por tanto, la comunicación y la promoción deben ser acordes a las características de la historia y en sintonía con el público al que se dirige. Conviene aceptar que el mercado es heterogéneo, con características y comportamientos distintos. En Internet hay que ser selectivo por esta razón es importante delimitar el segmento o sector del público al que se desea llegar. Cuanto mejor conozcamos sus características psicosociales, más fácil será construir un mensaje que utilice sus mismos códigos comunicativos, sintonice con sus intereses y expectativas y despierte su interés. Se trata de encontrar una idea con relevancia emocional para el público -los denominados insights- para conectar con él y ofrecerle una experiencia que movilice sus recursos afectivos. Las emociones juegan un papel fundamental en la codificación, almacenamiento y el recuerdo los mensajes, que a su vez sirven de base para nuestras decisiones. Obtener insights a partir del conocimiento del público objetivo es una de las tareas más importantes de la comunicación, por lo que debe ponerse en manos de profesionales (Álvarez, 2012).

\section{¿En qué medios? Evaluación y selección}

La información recabada del público objetivo va a ser fundamental para determinar cómo utilizar el universo de posibilidades que hay para comunicarla. No se trata de discernir entre campaña online o campaña tradicional. Todos son medios -cada uno con sus particularidades- que tienen que estudiarse en función del público objetivo y conseguir estar en los más afines.

Es importante la diferenciación de la oferta (offline y online), aunque hay que gestionar la integración de todos los canales para atender las necesidades de un público acostumbrado a interactuar a través de diferentes medios simultáneamente: televisión, prensa, redes sociales, blogs,...Con una combinación de todos los medios, se logrará una sinergia para cumplir con el objetivo. 


\section{¿Cuándo? Calendario y fases de la promoción}

Dentro de la estrategia de marketing online es necesario programar por adelantado -incluso antes del rodaje- las fases de la promoción y las acciones en las que se van a ir desvelando detalles de la película y dosificando en pequeñas píldoras hasta el momento del estreno. El objetivo es crear expectación y despertar el interés del público y futuro espectador. La elaboración de un calendario para las acciones de comunicación y promoción puede ser una herramienta muy útil para la gestión y el mantenimiento de la estrategia ya que permite observar de un vistazo los temas cubiertos, los canales empleados y los tiempos de distribución. Además de la fecha de publicación, conviene detallar el tipo de acción, su formato, el canal a través del que va a ser distribuido, e incluso los tags o hastags a incluir en las comunicaciones.

¿Y cuándo se acaba la campaña? La agencia Jet Set Studios, una de las más activas en el entorno online entre los estudios de Hollywood, ofrece algunas pistas: "Nosotros aguantamos tras el estreno como un mes y luego retomamos para el DVD". Durante ese tiempo la clave es una presencia estratégica sólo en aquellas plataformas y redes sociales en las que el público objetivo de la película pasa mayor tiempo. 


\section{PRESUPUESTO}

¿Cuánto vamos a invertir en la promoción?

2. DEFINIR EL PRODUCTO-PELICULA

¿Qué queremos contar?
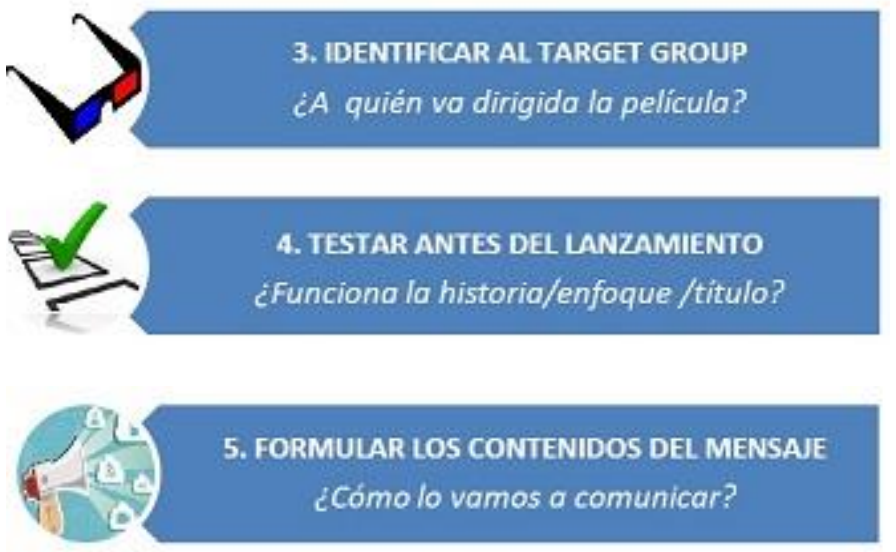

6. PLANIFICACIÓN DE MEDIOS

¿Cuáles son los mas afines a nuestro público?

7. CALENDARIO Y FASES DE LA CAMPAÑA

¿Cuándo programar las acciones de promoción ?

Figura 1. El briefing del filmarketing en 7 pasos

\section{ALGUNAS ESTRATEGIAS Y ESTUDIOS DE CASO}

Internet ha abierto nuevos modos de promocionar una película más allá de los medios tradicionales. En este nuevo paradigma el público y consumidor pasa a tener una participación activa que obliga al sector audiovisual y cinematográfico a utilizar nuevas herramientas de comunicación y promoción y adaptar los contenidos de las campañas a los requerimientos de los consumidores digitales.

Hoy por hoy, una campaña de éxito, es decir, que convierta a los internautas en espectadores, es la que consigue involucrarles generando un vínculo emocional que les haga sentir parte de la película, de forma que quieran compartir esos sentimientos con otros amigos una y otra vez. Ésta es la clave de la nueva promoción de la que citamos algunos casos de éxito recientes en Estados Unidos y en España.

Es el caso de la película "Ted" sobre un oso de peluche malhablado cuya campaña de promoción comenzó seis meses antes del estreno. Como en otros casos, se inició hablando sobre la película y publicando 
imágenes y vídeos hasta que decidieron sacar al personaje de la película y convertirlo en real. Le abrieron sus propios perfiles de Twitter y Facebook (@TedEsReal era su Twitter en España, @WhatSaidTed, en EE.UU.) y comenzaron a escribir como si hablara Ted, entonces llegó la eclosión. Cada publicación provocaba la interacción y la respuesta de los internautas, potenciales y futuros espectadores. Las cifras hablan solas: siete millones de fans en Facebook, entre 50.000 y175.000 clicks en 'Me gusta' en cada post, más de700.000 seguidores en Twitter y, lo mejor 54,4millones de dólares el primer fin de semana en Estados Unidos y, casi 600 millones en todo el mundo (Crespo, 2013).

"Lo imposible" y "Las aventuras de Tadeo Jones" lograron llenar las salas de cine y lograron dinamizar el sector propiciando la venta del 56\% de las entradas del año 2012 en España (Martos, 2012). Una de las claves deltaquillazo de estas dos películas de la productora Telecinco Cinema ha estado en la promoción. Ambas campañas comenzaron a fraguarse muchos meses antes de lanzarse contando con la participación de todos los canales de Mediaset para encontrar los mejores espacios, los mejores contenidos y tono y el ritmo más adecuado para difundir los principales elementos de comunicación de cada película. La emisión de un amplio número de pases de autopromociones, cortinillas, pathfinders, avances exclusivos, y documentales de making of conformaron la potente campaña de publicidad en antena diseñada por Mediaset España, a lo que hay que sumar el boca a boca provocado por la buena calidad de ambas películas.

En el caso de Tadeo, desde su aparición en la gala de los Goya 2012 hasta la fecha del estreno -31 de agosto, el personaje se convirtió en una referencia en todo tipo de eventos para los que se elaboraron piezas específicas: la Eurocopa, el Mundial de Motociclismo, Roland Garros, las campanadas de Fin de Año...El estreno constituyó un éxito convirtiéndose en la película española de animación más taquillera de la historia, con estrenos en todo el mundo y reconocida por la Academia con tres Premios Goya.

Por su parte, "Lo imposible" con un gran nivel técnico y artístico y una historia que no dejaba indiferente a nadie se convirtió en la película con mejor estreno en España de todos los tiempos (Belinchón, 2012). A día de hoy, es la cinta española más taquillera de la historia y la segunda más vista, solo superada por "Avatar". Con una estudiada campaña, hecha con previsión y con la colaboración de todas las partes implicadas, la película estuvo presente en todos los medios a través de cuidadas apariciones en prensa.

A nivel internacional tras cosechar algunos de los galardones internacionales más importantes, incluidas las nominaciones de Naomi Watts a Mejor Actriz Dramática en los Globos de Oro y Mejor Actriz Protagonista en los Oscar de Hollywood. 


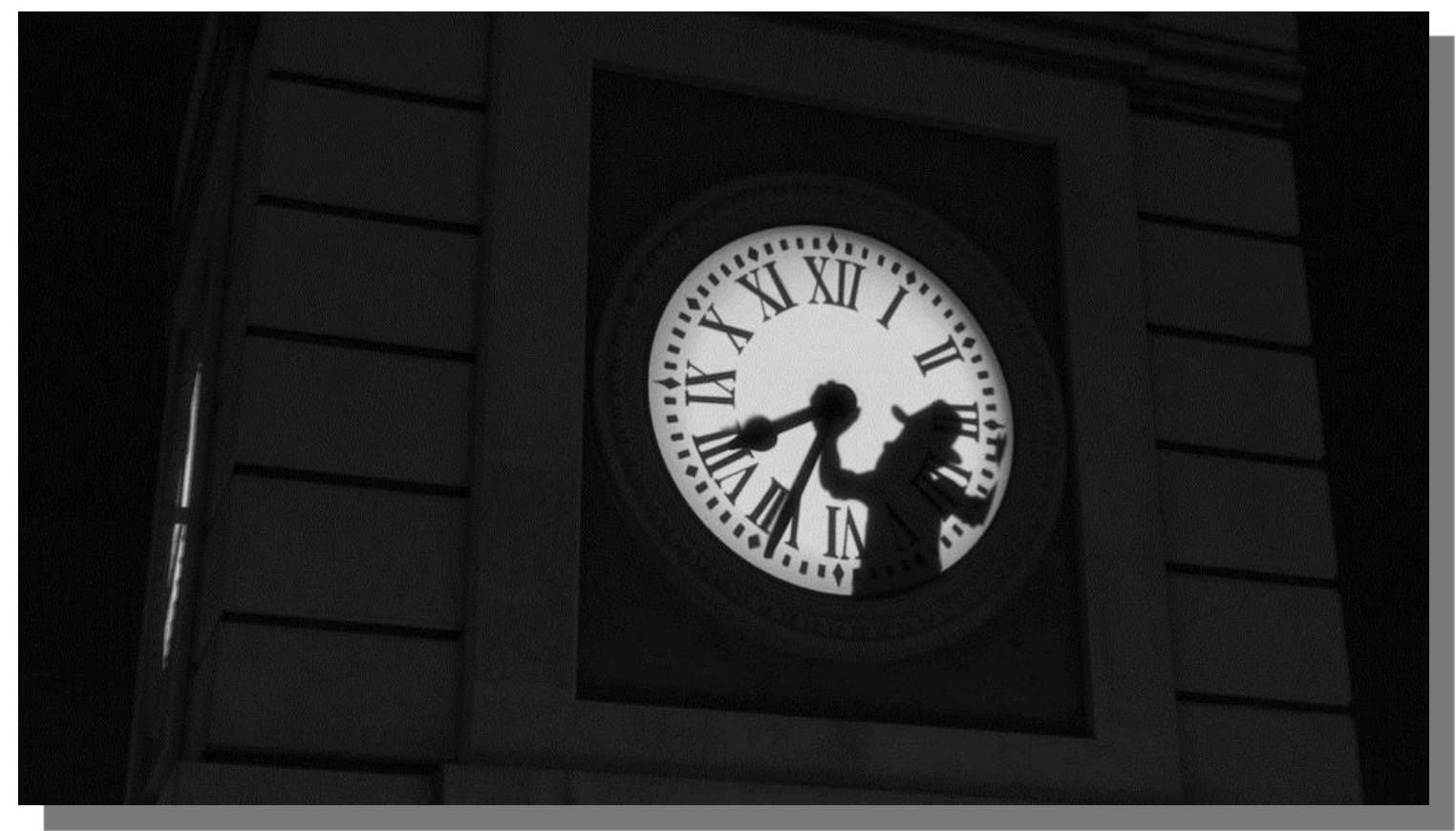

Figura 2. Mediaset España estrenó una pieza especial de Tadeo Jones en su emisión de las campanadas de Fin de Año 2012.

Los resultados de taquilla de "Ocho apellidos vascos" reafirma el éxito de la estrategia de comunicación 360 de Mediaset, que ha vuelto a repetir la fórmula incluyendo la emisión de un amplio número de pases de autopromociones y el refuerzo de las webs y redes sociales de la compañía (Telecinco Cinema, 2014). Además, ha desarrollado un formato más innovador: piezas específicamente producidas y protagonizadas por sus principales personajes, en las que han ofrecido reflexiones en tono de humor sobre diferentes tópicos entre vascos y andaluces. El próximo 29 de agosto Telecinco Cinema lanzará "El Niño", considerada como la película más ambiciosa del año para la que Mediaset ha preparado una gran campaña de marketing y comunicación con la participación de todos los canales del grupo (Fernández, 2014).

Señala López Lavigne (2013) que se impone cada vez más el modelo 365, la correlación desarrollada desde una compleja red de redes que emiten mensajes cada vez más simples, viralizados y, sobretodo, la generación de eventos multimedia fuera del ámbito de lo puramente cinematográfico. Se trata de retos de carácter inmediato, teniendo en cuenta la transformación imparable de la tecnología que repercute en los hábitos de consumo.

Para el lanzamiento de "Los amantes pasajeros" la productora El Deseo diseñó una estrategia de promoción muy diversificada generada en su mayor parte durante el periodo de postproducción de la película, poniendo especial énfasis en las nuevas tecnologías, sin olvidar los medios tradicionales. El gasto en publicidad ha sido un $20 \%$ más que en "La piel que habito" y el uso de las redes sociales ha sido muy importante, (Almodóvar, 2013). 
Fieles a la cultura del póster, cuidan de un modo especial el cartel promocional, trabajando con reconocidos artistas e ilustradores - Zulueta, Gatti y Mariscal, entre otros- que aporten expresividad, buen gusto y misterio en dosis suficientes para captar la atención (Tabuenca, 2011). No obstante, en la promoción se han desarrollado numerosos contenidos digitales y eventos para conectar con el público: vídeos para aprender la coreografía de los personajes de la película un libro interactivo en iTunes de descarga gratuita con contenido multimedia, imágenes exclusivas, making of e incluso el diario de rodaje del propio Almodóvar, y la organización de un flashmob en la madrileña Plaza de Callao un día después del estreno, evento convertido en noticia transmitida por televisión, comentada en medios impresos y viralizado en Internet con vídeos subidos por usuarios y medios tras la celebración del acontecimiento. Este título ha batido todos los récords de anteriores películas, convirtiéndose en el mejor estreno de toda la carrera del director manchego, con más de 1,86 millones de euros.

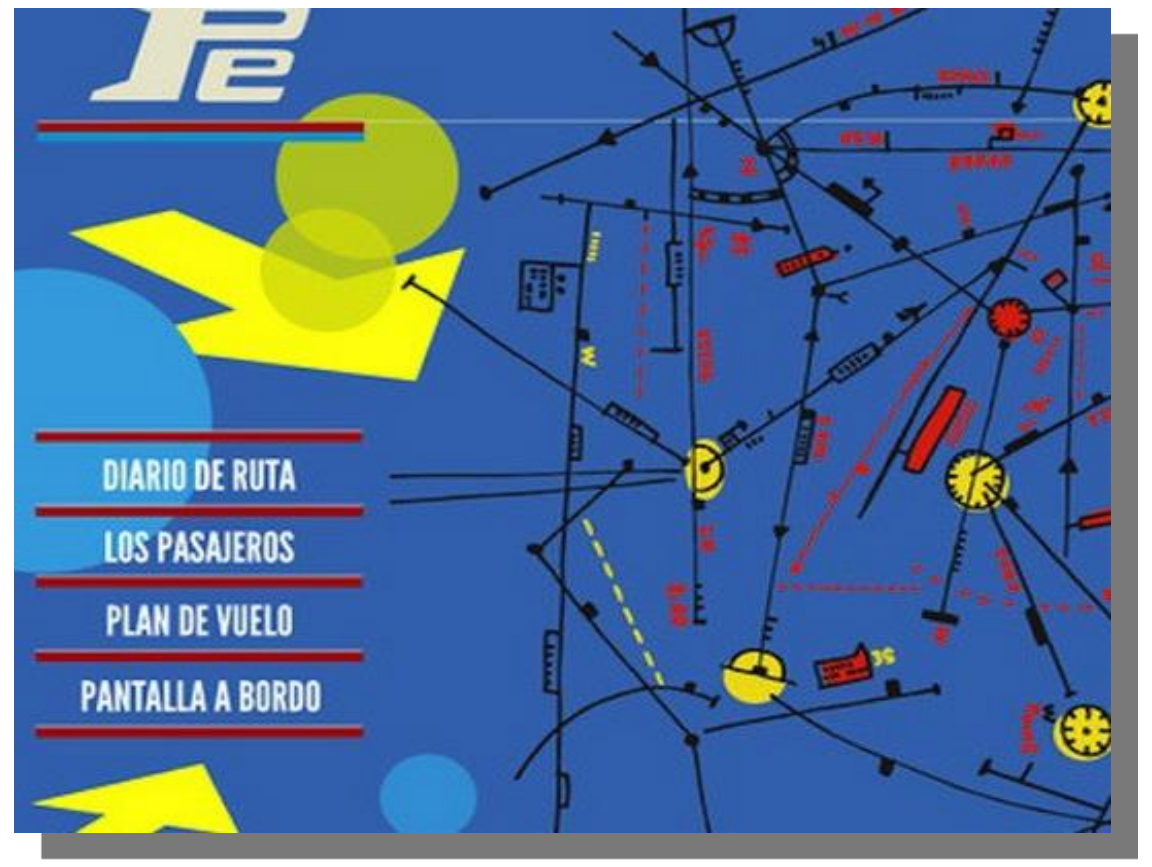

Figura 3. Libro interactivo en iTunes con contenido extra de la última película de Almodóvar "Los amantes pasajeros" (2013)

Parece lógico pensar que la etapa de marketing y publicidad de una película comienza tras la fase de postproducción, sin embargo nos encontramos casos en los que, antes de que se ruede la película ya se han elaborado unas fases de promoción para ir ofreciendo de forma periódica pequeños detalles de la obra en forma de píldoras para suscitar el interés y el boca a boca de los usuarios.

Es el caso de "Blancanieves y la leyenda del cazador" promocionada en el Comic Con de San Diego en 2011 sin haber sido rodada. ¿Qué es lo que atrajo? Los actores Kristen Stewart (Crepúsculo), Charlize Theron en el papel de bruja y Chris Hemsworth (el Thor de Marvel), fotos de producción y detalles del rodaje.

Un ejemplo más reciente, es la película de Julio Medem, -“Ma Ma”. En pleno rodaje, habiendo cambiado las localizaciones de Madrid por las de las de Tenerife y a pesar de no conocerse la fecha de estreno, ya se han 
lanzado entrevistas con la actriz protagonista -Penélope Cruz- el primer cartel oficial de la película y el making of (El periódico, 7 de julio 2014). La actriz constituye el principal reclamo de la historia, cuyas apariciones en público, declaraciones e imágenes captadas durante el rodaje se han difundido en prensa y televisión y han generado todo tipo de comentarios en las redes sociales sobre su personaje, su cambio de imagen para la película, etc. Marketing y expectación coste cero. No hay duda, el presente, y sobre todo, el futuro de la promoción está en Internet.

\section{CONCLUSIONES}

El planteamiento del marketing y la promoción del cine se han redefinido en el entorno digital, lo que obliga al sector audiovisual a adaptar los contenidos de las campañas de promoción a los requerimientos de los consumidores digitales, empleando nuevas herramientas y estrategias de comunicación para atraer a los espectadores.

Conviene diseñar una estrategia de comunicación diversificada, con contenidos y formatos (vídeos, fotos, juegos, apps, etc.) que ofrezcan información adicional y sobre todo, que se puedan compartir. El contenido generado por el usuario ha pasado a tomar un lugar relevante siendo uno de los modos en que se informan, y se relacionan influyendo en sus decisiones de uso/consumo. Por esta razón las acciones en redes sociales que se comparten de usuario a usuario juegan un papel clave.

La rentabilidad depende del conocimiento del mercado. Para garantizar la efectividad de cualquier campaña resulta clave conocer las características del público objetivo, lo que va a facilitar a los creativos y profesionales el desarrollo contenidos relevantes que respondan a sus intereses y expectativas así como la formulación de un mensaje atrayente que utilice sus mismos códigos. La información recabada también va a ayudar a optimizar la inversión del presupuesto, seleccionando las acciones más efectivas y los medios más afines al público objetivo.

Es importante considerar una oferta de contenidos multiplataforma (web, blogs, redes sociales, etc.) reforzando la posibilidad del público de acceso y consumo de información desde distintos dispositivos (ordenador, tablet, móvil...), en cualquier momento y en cualquier lugar.

Finalmente señalar que cada medio tiene unas características propias y requiere formas de comunicación diferentes, en relación con los distintos grupos o segmentos del público a los que se dirijan. La planificación y selección de medios -ya se trate tradicionales, o medios online- debe ser resultado del estudio de cada uno de ellos, que debemos conocer tanto como al público objetivo. 


\section{REFERENCIAS}

Academia. Revista del cine español (2013). La promoción, una pieza clave, no 201, junio.

ALMODÓVAR, Agustín (2013). "Una prolongación lógica de la película", Academia. Revista del cine español, nํ2 201, pp. 12-13.

ÁLVAREZ RUÍZ, Antón (2012). La magia del planner. Cómo la planificación estratégica puede potenciar la comunicación persuasiva. Madrid: ESIC-Business Marketing School.

BELINCHÓN, Gregorio. 'Lo imposible' consigue el mejor estreno de la historia del cine en España, elpais.com,

http://cultura.elpais.com/cultura/2012/10/15/actualidad/1350292862 967960.html (2014-07-07)

BRETONES, Gloria (2013). "Cómo el marketing online puede salvar al cine español”, Academia. Revista del cine español, no201, pp. 18-19.

CRESPO, Irene (2013). “No es promocionar, es contar historias”, Academia. Revista del cine español, no 201, pp. 20-21.

“Estrategias y ejemplos de marketing de cine” (2012). Símbolo Ingenio Creativo. http://blog.simboloic.es/estrategias-y-ejemplos-de-marketing-cinematografico-cine/

FERNÁNDEZ, Juan M. (2014). "Cómo convertir una película española en un fenómeno de masas", elconfidencial.com. http://www.elconfidencial.com/cultura/2014-07-07/como-convertir-una-peliculaespanola-en-un-fenomeno-de-masas 156120/ (2014-07-07)

GARCÍA FERNÁNDEZ, Emilio (2013). “Consolidar la imagen a través de la comunicación”, Academia. Revista del cine español, no 201, p.8.

GARCÍA, Yago (2013). “Cómo vendemos esta película? La crisis del marketing de cine”, Cinemanía, abril.

GUTIÉRREZ, Maㅡ Luisa. (2013). “Cómo vender una película”, Academia. Revista del cine español, no 201, pp.10-11.

IGLESIAS, Ángel (2013). “Comunicación siglo XXI”, Academia. Revista del cine español, № 201, pp.6-7.

LAREMA, Damiá. “Cine y marketing viral 2.0: El impacto de crear expectación” (2013). Taos. Agencia de Publicidad de Servicios Plenos. http://www.taos.es/blog/cine-y-marketing-viral-2-0-el-impacto-decrear-expectacion (2014-07-10)

LÓPEZ LAVIGNE, Enrique (2013). “Promoción«fantasma», Academia. Revista del cine español, no 201, p.15. 
MARCO, Patricia; BARROIS, Ghislain (2013). “Con talento y algo de suerte”, Academia. Revista del cine español, no 201, p.16.

MARQUEZ, Emilio (2010). "Detalles del nuevo marketing 2.0 en el cine". http://emiliomarquez.com/2010/08/18/detalles-del-nuevo-marketing-2-0-en-el-cine/ (2014-07-15)

MARTOS, David (2012). "La receta de "Lo imposible" y “Tadeo Jones" vuelve a llenar los cines". Abc.es, 2012/10/17. Disponible en: http://www.abc.es/20121017/cultura-cine/abci-loimposible-tadeojonestengoganasdeti-taquilla-201210161759.html (2014-07-10)

ORTEGA HERMIDA, Camila (2014). "Storytelling», una pieza clave para conectarse con sus clientes. Disponible en: http://www.youngmarketing.co/storytelling-una-pieza-clave-para-conectarse-con-susclientes/ (2014-07-10)

SANAGUSTÍN, Eva. Qué es el marketing de contenidos. http://www.marketingdecontenidos.es/faqs/que-es-el-marketing-de-contenidos (2014-07-07)

TABUENCA BENGOA, María (2011). "El «leit motiv» de la estética de Pedro Almodóvar analizado a través de la cartelística de su obra", Index comunicación, no 1, pp. 89-144. http://dialnet.unirioja.es/servlet/articulo?codigo=3820284 (2014-07-15)

Telecinco Cinema (2014). “Ocho apellidos vascos" arrasa en taquilla. www.publiesp.es/NPexitodetaquilla PUBFIL20140318 0003.pdf (2014-07-15) 